\title{
LENDO EM FRANCÊS LEIO O MUNDO: SIGNIFICAÇÕES PRODUZIDAS POR ALUNOS DE UMA ESCOLA PÚBLICA AMAPAENSE SOBRE O ENSINO DA LÍNGUA FRANCESA PARA A COMUNICAÇÃO INTERFRONTEIRIÇA
}

\author{
LECTURA EN FRANCÉS LEÍ EL MUNDO: SIGNIFICADOS PRODUCIDOS POR \\ ESTUDIANTES DE UNA ESCUELA PÚBLICA EN AMAPÁ SOBRE LA ENSEÑANZA \\ DEL LENGUA FRANCESA PARA LA COMUNICACIÓN TRANSFRONTERIZA
}

\author{
READING IN FRENCH I READ THE WORLD: MEANINGS PRODUCED BY \\ STUDENTS FROM A PUBLIC SCHOOL IN AMAPÁ ON FRENCH LANGUAGE \\ TEACHING FOR CROSS-BORDER COMMUNICATION
}

\author{
Mesaque Silva CORREIA ${ }^{1}$ \\ Neuton Alves de ARAÚJO2 \\ Paulo Renzo GUIMARÃES JÚNIOR ${ }^{3}$
}

RESUMO: Neste texto o objetivo é o de analisar as significações que alunos de uma escola pública amapaense vêm produzindo sobre o ensino da Língua Francesa para a comunicação interfronteiriça. Para alcançar o objetivo proposto, nos apropriamos dos pressupostos teóricometodológicos da Teoria Histórico-Cultural/Teoria da Atividade. A questão que orientou esta pesquisa foi: Nos discursos dos alunos de uma escola pública amapaense, quais as suas possíveis significações (sentidos e significados) produzidas sobre o ensino da Língua Francesa para a comunicação interfronteiriça? Participaram do estudo 5 (cinco) alunos do $3^{\circ}$ ano do Ensino Médio de uma escola pública amapaense, localizada na divisa Brasil/Guiana francesa que tem a disciplina Língua Francesa como componente curricular obrigatório. Especificamente sobre a produção dos dados, se empregou a entrevista semiestruturada. Os resultados da pesquisa evidenciam que se faz necessário pensar em políticas linguísticas que valorizem o ensino de línguas com enfoque em propostas culturalmente marcadas, que se baseiem, sobretudo, na relação entre língua e cultura. Além disso, os sentidos produzidos, a partir dos discursos dos alunos investigados, são demonstrativos de que, para estes alunos a aprendizagem da Língua Francesa medeia não somente a comunicação franca mas, também, a aprendizagem dos elementos da cultura francesa.

PALAVRAS-CHAVE: Produção de significações. Língua francesa. Comunicação fronteiriça. Formação humana.

RESUMEN: En este texto el objetivo es analizar los significados que los alumnos de una escuela pública de Amapá vienen produciendo sobre la enseñanza de la lengua francesa para

${ }^{1}$ Universidade Federal do Piauí (UFPI), Teresina - PI - Brasil. Professor Adjunto no Departamento de Métodos e Técnicas de Ensino. Doutorado em Educação Física (USTJ). ORCID: https://orcid.org/0000-0002-02587111.E-mail: mesaquesilvacorreia@ufpi.edu.br

${ }^{2}$ Universidade Federal do Piauí (UFPI), Teresina - PI - Brasil. Professor Permanente do Mestrado Nacional Profissional em Ensino de Física. Doutorado em Educação (USP). ORCID: https://orcid.org/0000-0003-43209536.E-mail: doutor.neuton@ufpi.edu.br

${ }^{3}$ Universidade Federal do Piauí (UFPI), Teresina - PI - Brasil. Graduando no Curso de Educação Física. ORCID: https://orcid.org/0000-0003-0873-8328.E-mail: renzo-acupuntura@hotmail.com 
la comunicación transfronteriza. Para lograr el objetivo propuesto, nos apropiamos de los supuestos teórico-metodológicos de la Teoría Histórico-Cultural / Teoría de la Actividad. La pregunta que orientó esta investigación fue: En los discursos de estudiantes de una escuela pública de Amapá, ¿cuáles son sus posibles significados (sentidos y significados) producidos sobre la enseñanza de la lengua francesa para la comunicación transfronteriza? Participaron del estudio 5 (cinco) estudiantes del 3er año de Bachillerato de una escuela pública en Amapá, ubicada en la frontera de Brasil / Guayana Francesa, que tiene el idioma francés como componente curricular obligatorio. Especificamente en la producción de los datos, se utilizaron entrevistas semiestructuradas. Los resultados de la investigación muestran que es necesario pensar en políticas lingüisticas que valoren la enseñanza de lenguas con un enfoque en propuestas culturalmente marcadas, que se basan, sobre todo, en la relación entre lengua y cultura. Además, los significados producidos, a partir de los discursos de los estudiantes investigados, son demostrativos de que, para estos estudiantes, el aprendizaje de la lengua francesa media no solo la comunicación franca, sino también el aprendizaje de los elementos de la cultura francesa.

PALABRAS CLAVE: Producción de significados. Idioma francés. Comunicación fronteriza. Formación humana.

ABSTRACT: In this text the objective is to analyze the meanings that students from a public school in Amapa have been producing on the teaching of the French language for crossborder communication. To achieve the proposed objective, we appropriate the theoreticalmethodological assumptions of Historical-Cultural Theory / Activity Theory. The question that guided this research was: In the speeches of students from a public school in Amapá, what are their possible meanings (senses and meanings) produced about the teaching of the French language for cross-border communication? Participated in the study 5 (five) students of the 3rd year of High School of a public school in Amapá, located on the border of Brazil / French Guiana, which has the French language as a mandatory curricular component. Specifically on the production of the data, semi-structured interviews were used. The results of the research show that it is necessary to think about linguistic policies that value the teaching of languages with a focus on culturally marked proposals, which are based, above all, on the relationship between language and culture. In addition, the meanings produced, from the speeches of the investigated students, are demonstrative that, for these students, the learning of the French language mediates not only frank communication but also the learning of the elements of French culture.

KEYWORDS: Production of meanings. French language. Border communication. Human formation.

\section{Introdução}

Neste texto são trazidos e discutidos resultados de um estudo, amparado nos pressupostos da Teoria Histórico-Cultural/Teoria da Atividade, que se propôs a analisar as significações que alunos de uma escola pública amapaense vêm produzindo sobre o ensino da Língua Francesa para a comunicação interfronteiriça. É parte de uma pesquisa mais ampla, a 
qual foi realizada na região norte do Brasil, na cidade de Oiapoque no Estado do Amapá, envolvendo alunos do $3^{\circ}$ ano do Ensino Médio de uma escola pública que se encontra localizada na divisa Brasil/Guiana Francesa. No Projeto Político Pedagógico (PPP) desta escola, há a disciplina de Língua Francesa como componente curricular obrigatório.

É sabido que não são raras as pesquisas que denunciam a má qualidade do ensino e da aprendizagem de língua estrangeira nas escolas públicas brasileiras. Nessa mesma direção, há estudos que apresentam como resultados indícios de significações produzidas por pais, responsáveis e/ou alunos de que as condições objetivas e subjetivas possibilitadas pelas escolas não favorecem a aprendizagem de uma língua estrangeira na perspectiva da formação humana, ou seja, aquela formação que garanta ao aluno o salto qualitativo de suas significações de homem, de mundo e de sociedade, levando-o à tomada de consciência da necessidade de refletir e de se apropriar dos conhecimentos teórico-científicos, os quais são os conhecimentos universais mais avançados e desenvolvidos pela humanidade (ALASMARTINS, 2014; GARCÍA PAREJO; MARTINS, 2017; CEDRO; MOURA, 2017; AMBADIANG, 2018; WOLF-FARRÉ, 2018; MALAVER, 2020).

Em linhas gerais, estes estudos questionam a função e relevância social e política de se ensinar e aprender uma língua estrangeira, bem como uma perspectiva de formação que se contraponha à visão utilitária e reducionista ainda muito presente na atividade pedagógicas dos professores da Educação Básica. Desse modo, buscam compreender as significações (sentidos e significados) que alunos e professores têm desenvolvidos sobre o ensino de línguas nas escolas no que tange ao desenvolvimento cognitivo do aluno.

Isto posto, a necessidade de se pensar na organização do ensino das línguas estrangeiras no cenário nacional, se torna cada vez mais emergencial, especialmente. Por que dizemos isso? Por sabermos que na escola, muitas vezes, o desenvolvimento desta disciplina (ou campo de saber) é centrado apenas nos aspectos linguístico e instrumental do conteúdo. Em outras palavras, na atividade pedagógica, o foco são a aprendizagem gramatical, o vocabulário de forma artificial e, quase sempre, desvinculados dos interesses e necessidades dos alunos, o que dificulta a aprendizagem comunicativa e por extensão significativa, promotora do desenvolvimento (ALMEIDA FILHO, 2007). Como tão bem enfatizado por Vigotski (2009, p. 246-247),

Esse processo de desenvolvimento dos conceitos ou significações das palavras requer o desenvolvimento de toda uma série de funções como a atenção, a memória lógica, a abstração, a comparação e a discriminação, e todos esses processos psicológicos sumamente complexos não podem ser simplesmente memorizados, simplesmente assimilados [...] O professor que 
envereda por esse caminho costuma não conseguir senão uma assimilação vazia de palavras, um verbalismo puro e simples que estimula e imita a existência dos respectivos conceitos na criança mas, na prática, esconde o vazio.

Diante do exposto, torna-se possível sintetizarmos que, no decorrer do Ensino Médio, em especial no contexto da escola pública, os alunos além de não receberem uma formação humana, estes acabam saindo da Educação Básica sem alcançar os objetivos mínimos propostos. Em decorrência disso, buscam fazer cursos básicos de idiomas, quando têm oportunidades, a fim de que, de certa forma, possam criar as condições objetivas para sobreviverem às necessidades impostas por uma sociedade que se preocupa mais com o mercado de trabalho, ou seja, com a lógica do capital, do que com a formação na perspectiva aqui defendida neste estudo (SANTOS; PORTO, 2011).

Todas essas considerações convergem às reflexões de Marques (2016). Nas esteiras do pensamento do autor em tela, o papel do ensino de línguas estrangeiras no currículo escolar é de transformar os alunos e as alunas em cidadãos do mundo. "Ser cidadão" envolve a compreensão sobre que posição/lugar uma pessoa (o aluno/o cidadão) ocupa na sociedade" (BRASIL, 2014, p. 91).

Dessa forma, possibilitar a leitura do mundo e da palavra é um dos principais objetivos para se apropriar de uma língua estrangeira. Por esse motivo, a atividade pedagógica deve estar atrelada ao universo de quem aprende, a seus interesses e necessidades, se apresentando como possibilidade da formação de uma consciência crítica da heterogeneidade e da diversidade sociocultural e linguística (BRASIL, 2014).

A rigor, as críticas aqui apresentadas, como educadores, entendemos que o aluno ao aprender uma nova língua, certamente, está descortinando o mundo da vida e o mundo do conhecimento escolarizado. Dessa forma, se abrem possibilidades para o seu autoconhecimento e passa, portanto, a observar a sua própria existência e a do outro, bem como a reconhecer e respeitar as diferenças culturais, sociais e pessoais e, consequentemente, desenvolverá a função comunicativa e sociocultural acerca dos conceitos apropriados, internalizados.

Assim, a premissa que defendemos neste estudo é que o ensino de língua estrangeira deve ser compreendido como um processo de conscientização de si e do outro, capaz de romper os limites de trocas de informações e, ainda, levar o aluno a observar que há diferenças nas formas de se comunicar e que essas diferenças estão associadas ao seu contexto social, à história e à experiência de vida dos povos (SARMENTO, 2016). Desse modo, a questão que orientou esta pesquisa foi: Nos discursos dos alunos de uma escola pública 
amapaense, quais as suas possíveis significações (sentidos e significados) produzidas sobre o ensino da Língua Francesa para a comunicação interfronteiriça?

É oportuno explicarmos que essas diferenças representam distintas maneiras de se comunicar com o mundo e de representar esse mundo, ou seja, refletem diferentes "visões de mundo", posto que a diversidade das línguas não se resume a uma diversidade de sons e de sinais, mas é a sinalização de uma diversidade de visões de mundo (LIMA, 2012).

Este texto, além da introdução, foi organizado com seções voltadas a reflexões teóricas sobre a categoria significação (sentido e significado), aos procedimentos metodológicos, aos resultados e discussões (análise dos dados) e às considerações finais.

\section{Produção de significações (sentidos e significados) sob o enfoque da Teoria Histórico- Cultural/Teoria da Atividade: algumas reflexões teóricas}

A categoria significação, representada pelo par dialético sentido pessoal e significado social, é um dos objetos de estudo dos russos Vigotski (2009) e Leontiev (1978; 1983; 2018), maiores expoentes da Teoria Histórico-Cultural/Teoria da Atividade.

Com base nas premissas de Leontiev, ao se destacar a sua obra: O desenvolvimento do psiquismo (LEONTIEV, 1978, p. 94), a significação, compreendida por ele como uma das categorias mais elaboradas pela psicologia moderna da sua época, nada mais do que

[...] a generaliza ão da realidade que cristalizada e fixada num vector sens vel, ordinariamente a palavra ou a locu ão. a forma ideal, espiritual da cristaliza ão da experi ncia e da pr tica sociais da humanidade. A sua esfera das representa es de uma sociedade, a sua ci ncia, a sua 1 ngua existem enquanto sistemas de significa ões correspondentes. A significa ão pertence, portanto, antes de mais nada ao mundo dos fenómenos objectivamente hist ricos.

Ao explicitar que, "a significa ão pertence, portanto, antes de mais nada ao mundo dos fenómenos objectivamente hist ricos", no nosso entender, Leontiev (1978) está se referindo ao conceito de significado, um dos sistemas de significação que o indivíduo se depara a partir de suas relações com o meio social, de forma mais intensa na escola. Na verdade, é o primeiro sistema de significações experienciado pelos sujeitos, o qual não está diretamente ligado ao plano subjetivo do indivíduo, posto que tais significações já se encontram elaboradas e estruturadas pela própria humanidade. Em outras palavras, são significações que "[...] referem-se, assim, aos conteúdos instituídos, mais fixos, compartilhados, que são apropriados pelos sujeitos, configurados a partir de suas próprias subjetividades." (AGUIAR, 2006a, p. 14). Portanto, se trata de um processo que, conforme afirma Leontiev (1980, p. 66), “[...] 
Lendo em francês leio o mundo: significações produzidas por alunos de uma escola pública amapaense sobre ensino da língua francesa para a comunicação interfronteiriça

ocorre na atividade externa da criança com os objetos materiais e no intercâmbio prático que envolve.”. Logo, dizemos que o significado é social.

No palco dos debates sobre as significações, a categoria consciência se apresenta como o ponto de partida. Devemos significá-la não como um elemento pronto, inerte e, sim, compreendê-la no seu devir e desenvolvimento, determinado pelas rela es e condições objetivas postas no contexto social em que estão inseridos os sujeitos (LEONTIEV, 1978).

Com o desenvolvimento da consciência, embora seja uma necessidade para os sujeitos se apropriarem das significações, ou melhor, dos significados dos conceitos produzidos pela humanidade, pelo viés da Teoria Histórico-Cultural/Teoria da Atividade, o mais valorativo para os mesmos é a “ a estrutural funcional da consc ia”, pois “[...] o que constitui o conteúdo central e fundamental de todo o processo de desenvolvimento co" (VIGOTSKI, 2009, p. 285). E é aqui onde nos deparamos com outro sistema de significações: o sentido pessoal, o qual é consciente.

Com o intuito de melhor aprofundarmos essa problemática dos sistemas de significações, ou melhor, a diferença entre sentido e significado, Leontiev (1978, p. 97, grifo do autor), assim nos esclarece:

De um ponto de vista psicológico concreto, este sentido consciente é criado pela relação objectiva que se reflecte no cérebro do homem, entre aquilo que o incita a agir e aquilo para o qual a sua acção se orienta como resultado imediato. Por outras palavras, o sentido consciente traduz a relação do motivo ao fim. Devemos apenas sublinhar que não utilizamos o termo "motivo" para designar o sentimento de uma necessidade; ele designa aquilo em que a necessidade se concretiza de objetivo nas condições consideradas e para as quais a atividade se orienta, o que a estimula.

Cabe, assim, observarmos que os sentidos pessoais se manifestam nos significados produzidos pelos sujeitos, estando estes atrelados aos fenômenos subjetivos, à subjetividade. São, desse modo, criados a partir dessa relação, tornando-se reflexos no cérebro dos sujeitos, como já dito por Leontiev (1978, p. 97), “[...] entre aquilo que o incita a agir e aquilo para o qual a sua acção se orienta como resultado imediato.

Sobre essa questão, é oportuno enfatizarmos que na efetivação do processo de desenvolvimento das significações a linguagem é um dos elementos essenciais. "Pela linguagem o homem se apropria das significações sociais e a elas atribui um sentido pessoal associado aos seus motivos e necessidades.” (LONGAREZI; FRANCO, 2017, p. 273).

Feitas as considerações, neste estudo uma discussão teórica sobre a categoria significação (sentidos e significados) se fez necessária. Ao incidirmos nosso olhar sobre o 
ensino e aprendizagem da Língua Francesa proporcionado aos alunos da escola pública amapaense, campo empírico desta pesquisa, certamente, encontraremos significações produzidas pelos alunos. Uma delas seria que os alunos a apropriação dos conhecimentos teórico-científicos, desenvolveriam significados da Língua Francesa como uma necessidade para a comunicação interfronteiriça e, sobretudo como "[...] uma educação cidadã, participativa, crítica, incluindo a a formação para a capacidade de pensar, de ter autonomia moral, a formação para o trabalho [...]" (TONET, 2006, p. 18).

Outra significação, possivelmente, seriam os sentidos que os alunos produzem sobre a atividade pedagógica dos professores que ensinam a Língua Francesa. Eis aqui a importância de se ênfase aos sentidos e significados desenvolvidos pelos alunos a respeito da inserção da disciplina Língua Francesa no currículo da escola da educação básica investigada.

\section{Procedimentos metodológicos}

Por considerarmos o problema, o objetivo e, sobretudo, o referencial teóricometodológico que assumimos neste estudo, trabalhamos com a pesquisa explicativa por corroboramos das ideias de Vigotski (2007), ao postular que devemos explicar e não nos limitarmos às descrições nominais do processo que compõe o fenômeno investigado, que no caso deste estudo são as significações produzidas por alunos sobre o ensino da Língua Francesa para a comunicação interfronteiriça. Tal pressuposto foi cunhado de "explica ão versus desc ão"(VIGOTSKI, 2007).

Nas condições postas, entendemos que o referido tipo de pesquisa substancia a produção de respostas sobre as significações relativas às experiências vivenciadas pelos alunos a respeito do ensino da Língua Francesa para a comunicação interfronteiriça.

Esclarecemos, ainda, que os 5 (cinco) alunos participantes, 3 (três) eram do gênero feminino e 2 (dois) do gênero masculino, com idade entre 16 e 17 anos. Por se tratar de alunos menores, os pais e/ou responsáveis de todos os alunos receberam esclarecimento prévio e detalhados acerca dos propósitos do estudo. Além disso, por adesão voluntária assinaram o Termo de Consentimento Livre e Esclarecido (TCLE), autorizando a participação de seus filhos na referida pesquisa. Nessas condições, também assinaram o Termo de Consentimento Assentimento Livre e Esclarecido (TALE), autorizando a participação nas atividades deste estudo.

A fim da garantia do anonimato dos nomes dos alunos investigados neste estudo, empregamos nomes fictícios: Aluno - 01, Aluna - 02, Aluno - 03, Aluna - 04 e Aluno - 05. 
Especificamente sobre a produção dos dados, utilizamos a entrevista semiestruturada. Para Aguiar e Ozella (2006b), se trata de uma técnica rica para a construção de dados em pesquisa por permitir o acesso aos processos psíquicos da produção das significações. $O$ roteiro de entrevista abordou os tópicos: Quais as significações do ensino de francês para a sua vida? De que forma as aulas de francês são realizadas? Qual utilização você faz do francês fora da escola? De que forma o francês ajuda na comunicação com os franceses habitantes na divisa Brasil/Guiana francesa?

Os dados produzidos em decorrência das entrevistas foram submetidos à proposta de Gaskins, Miller e Corsaro (1992). Estes autores indicam o uso da abordagem interpretativa quando o foco da investigação são as significações da ação humana frente a contextos culturais específicos. As entrevistas tiveram duração média de 40 (quarenta) minutos. Foram transcritas na íntegra e foi realizada uma análise-síntese dos dados no intuito de obtenção das principais mensagens-chave. Em seguida, foram extraídos os fragmentos dos discursos relevantes à compreensão do objetivo e problema da investigação.

Assim, para proceder sessão das análises (resultados e discussões), organizamos os dados em 2 (duas) categorias: 1) Significações inicialmente produzidas sobre a necessidade de se aprender a Língua Francesa; 2) Movimento de produção de novos sentidos da necessidade da Língua Francesa como formação humana.

\section{Resultados e discussões}

Nesta se ão, com o propósito de analisarmos as significações que alunos de uma escola pública amapaense vêm produzindo sobre o ensino da Língua Francesa para a comunicação interfronteiriça, procuramos nos aproximar das experiências vivenciadas pelos alunos, sujeitos deste estudo, na disciplina Língua Francesa. Dessa forma, para facilitar a análise dos dados produzidos através da entrevista semiestruturada, trabalhamos com as categorias: Significações inicialmente produzidas sobre a necessidade de se aprender a Língua Francesa; Movimento de produção de novos sentidos da necessidade da Língua Francesa como formação humana.

\section{Significações inicialmente produzidas sobre a necessidade de se aprender a Língua Francesa}

As significações, inicialmente, manifestadas pelos alunos, sujeitos desta pesquisa, sobre a necessidade de se aprender a Língua Francesa, emergem de suas necessidades e desejo 
de aprender a falar francês antes mesmo de terem no currículo do Ensino Médio esta disciplina como componente curricular obrigatório, produzidas a partir de contextos extraescolares, como é o caso da Aluna - 05, ao nos revelar que:

Sempre adorei música francesa e acho que esse foi meu principal estímulo para o estudo da língua na escola. Desde os 15 anos eu ficava muito tempo tentando entender e escrever as letras das músicas que eu gostava (les frères Jacques, Moustaki, Mouloudgi e é claro, Aznavour). Tinha loucura pelos musicais do Jacques Démy, Les parapluies de Cherbourg e Les demoiselles de Rochefort e sempre tentava entender e escrever as letras das músicas desses musicais. Por morarmos em uma área de fronteira, meus pais sempre me incentivaram a conhecer a cultura francesa. Quando eu cheguei à escola e comecei a estudar o francês, comecei a fazer associação das músicas e outras coisas que já sabia (Entrevista).

Nessa mesma linha de pensamento, podemos destacar o discurso da Aluna - 04:

Eu nunca tive dificuldade com o francês na escola. Aqui na cidade a gente já aprende algumas coisas desde pequeno. Quando a gente entra na escola e tem contato com a disciplina consegue compreender melhor o que fazemos lá rua, em casa. Tem algumas palavras que pronunciávamos errado, outras que achávamos que significava uma coisa e significa outra. Mas aqui na escola, para eu aprender mais rápido o vocabulário, eu sempre escrevo novamente todas as palavras e expressões, e busco verificar o contexto em que elas aparecem. E também associo a fala dos gringos e aos elementos da cultura francesa (Entrevista).

A respeito dos discursos dos alunos em tela, Lima (2012) afirma que a criança desde muito cedo recebe influências culturais dos diversos espaços sociais dos quais participa, a exemplo da igreja, da escola, da família, da comunidade do seu bairro, da sua cidade e de seu país. São, na verdade, influências culturais que ajudam na construção de uma maneira de falar que espelha uma cultura. O mesmo deve ocorrer na aprendizagem de uma língua estrangeira. No ato do processo de ensino e aprendizagem, o professor deve buscar estratégias de ensino que sejam capazes de associar o ensino da língua estrangeira às manifestações culturais. Isto porque, a língua é uma das partes mais importante da cultura, uma característica sine qua non para nos apropriarmos verdadeiramente em uma cultura estrangeira e nos comunicarmos nessa língua.

Podemos afirmar ainda, a partir da análise dos discursos apresentados pelos alunos 04 e 05 , que as significações produzidas por eles, inicialmente, acerca da necessidade de se aprender a Língua Francesa, evidencia que o contexto social e cultura se apresentam como alicerces para o desenvolvimento dos alunos. Há, dessa forma, certa indivisibilidade entre o aprendizado da Língua Francesa na escola e os aprendizados adquiridos extramuros escolares. 
Lendo em francês leio o mundo: significações produzidas por alunos de uma escola pública amapaense sobre ensino da língua francesa para a comunicação interfronteiriça

Para reforçar essa constatação, destacamos, ainda, as falas dos alunos 03 e 02 , respectivamente:

A partir dele posso mais, agora falo direto com gringo, é bom tanto pra mim como pra eles (Entrevista).

Quando comecei a cursar a disciplina de francês muitas coisas que a professora falava eu já sabia. Aqui no Oiapoque a gente é praticamente obrigado a conhecer o francês para sobreviver. Aqui a gente fala, canta, conta, briga, faz praticamente tudo em francês. Tem gente que vem da capital e precisa da gente para falar com os gringos. O bom disso tudo, é que na escola a gente só aprimora o que aprende na vida (Entrevista).

Todas essas significações produzidas pelos alunos 03 e 02 , inicialmente manifestadas sobre a necessidade de se aprender a Língua Francesa, convergem às ponderações de Brun (2004), ao alertar que, a partir do momento em que o ensino da língua estrangeira se alicerça no mundo vivido pelos alunos, a cultura é edificada e a aquisição da língua extrapola o universo da sala de aula, do ensino propriamente dito. Como diz Freire (1996), a "leitura do mundo precede a leitura da palavra.". Nessa perspectiva, podemos dizer que os conhecimentos prévios dos alunos referentes aos elementos linguísticos da Língua Francesa e da cultura francesa, certamente, contribuem para a aprendizagem deste campo de saber.

À luz desse quadro de análise, fica evidenciado o papel preponderante da linguagem, da comunicação no processo de desenvolvimento da produção de significados. Para Leontiev (1980, p. 65), “[...] o ve de significa ão a linguagem, mas a linguagem não o demiurgo da significa ão.”. E, para confrontar o pensamento deste ico, trouxemos fragmentos do discurso da aluna - 01 que, no mundo de consciência, assim, significa a importância da comunicação, da linguagem no contexto em foco:

A comunicação é talvez a coisa mais importante que a aprendizagem da língua francesa me proporciona. Mais é só uma das coisas, depois que aprendi eu interajo melhor com o povo de lá, parece que eles também valorizam mais as pessoas que falam a língua deles. São muitas coisas (Entrevista).

Dada essa importância da linguagem enquanto veículo de significação, encontramos nos estudos de Vigotski (2009) que, no seu processo de apropriação pelos sujeitos, se dá também a produção de novas significações, posto que ao longo deste desenvolvimento, o sistema de rela es e generaliza es contido numa palavra, consequentemente, avança. Para novamente confrontarmos esta situação, trouxemos fragmentos do discurso da aluna - 02 : "Falar com as pessoas, ajudar as pessoas, descobrir o que existe após a ponte". (Entrevista). 


\section{Movimento de produção de novos sentidos da necessidade da Língua Francesa como formação humana}

Para a análise dos dados produzidos para esta categoria, partimos do pressuposto de que, para que os conceitos trabalhados na disciplina Língua Francesa possa fazer parte da vida dos alunos e, consequentemente, possam ser significados como formação humana e, não simplesmente como uma disciplina com conteúdo programático e carga horária pré-definidos, "[...] não basta "passar" pelo ensino, senão que este deve ser "vivido", deve entrar a formar parte da vida do educando, deve ter para ele sentido vital.”, como nos revela Lontiev (1983, p. 247, tradução nossa). Eis aqui a necessidade da produção de novas significações que, no caso desta subseção analítica, são os sentidos.

Face o exposto, o sentido é uma relação e, desse modo, não se ensina. Porém, pode sofrer transformações. Para Leontiev (1983, p. 234, tradução nossa), se trata de uma significação "[...] desenvolvida, claramente conscientizada, dotando o educando de conhecimentos e atitudes correspondentes.”.

Nos discursos dos alunos selecionados para esta subseção apresentaremos indicativos da produção do sentido pessoal que os alunos, sujeitos deste estudo, desenvolveram na atividade de aprendizagem da disciplina Língua Francesa na perspectiva defendida por Leontiev (1983).

Acredito que a coisa mais importante seja a comunicação. O francês me possibilita descobrir as coisas, ler o que antes não sabia (Aluna - 01, Entrevista).

Conhecer o mundo (Aluna - 04, Entrevista).

Ele alimenta meus sonhos. Eu digo e o povo rir, mas ainda ganho o mundo. Acho que é isso, ganhar o mundo (Aluno - 05, Entrevista).

Ao falar francês não é só regras de outra língua que aprendo. Junto a ela eu aprendo a cultura do povo do lado de lá, eu posso falar com eles e eles falarem comigo [...]. Ninguém enrola ninguém (Aluno - 05, Entrevista).

As aulas de francês me ajudam não só na aprendizagem da língua francesa em si, ela me torna mais humana, mais cidadã. Poder se comunicar com os franceses e passar um pouco de nossa cultura para eles não tem preço. Sem o conhecimento do francês a gente só olha e sorrir para não chorar (Aluno 3, Entrevista).

Depois que comecei a falar francês tive acesso a mais coisas. Aqui na cidade quase todo mundo sabe um pouquinho do francês, a gente aprendi com os gringos. Mas estudar na escola é diferente, porque lá aprendemos para além da fala, aprendemos a cultura deles, e passamos a compreender o 
porquê deles agem de determinada forma, seus gestos corporais, seu sotaque (Aluno - 03, Entrevista).

Em linhas gerais, estes alunos apresentam uma nova significação, ou seja, um sentido pessoal a respeito da Língua Francesa para a comunicação interfronteiriça, para a vida deles, o qual pode ser sintetizado da seguinte forma: "ler o mundo". Isso reflete a relevância social e política do ensino da Língua Francesa para os alunos que vivem na área da fronteira, o que ainda pode ser constatado nos depoimentos:

Sem dúvidas a comunicação em francês facilita o diálogo. Eu leio tudo agora, e falo tudo com eles, eles me corrigem às vezes, mas eu descobrir um novo mundo com as aulas de francês [...] mon Dieu! (Aluno - 05, Entrevista).

Falar com os franceses em francês é uma das melhores coisas que a aprendizagem do francês me trouxe, depois que aprendi a falar em francês aprendi muitas coisas do lado de lá. Lá é outro mundo! (Aluna - 02, Entrevista).

Tais discursos demonstram que o mencionado ensino quando descentralizado do aspecto linguístico e instrumental do conteúdo e, portanto, vinculado aos interesses e necessidades dos alunos, contribui para o processo de formação humana, uma vez que, como reforça Araújo (2014), a língua é um produto da cultura. É o sentido pessoal que foi desenvolvido pelas alunas 01 e 04 , respectivamente, como explícito em suas falas:

Antes de iniciar as aulas de francês na escola, a gente se comunicava por gestos ou dependia da vontade dos outros, agora eu falo de boa com os gringos. Já aprendi muito só de conversar com eles, eles me ensinam e aprendem também comigo (Entrevista).

A importância tá na comunicação, na descoberta das coisas, da cultura francesa, mas não só dá deles, dá nossa também, aprendi nas aulas que influenciamos e sofremos influências culturais deles. Nosso mundo não acaba na fronteira, tem um pouquinho de Brasil do lado de lá (Entrevista).

De modo geral, quando os alunos apontam a relevância social e política da Língua Francesa para comunicação, para a leitura do mundo, estes estão vinculando as aprendizagens da língua aos valores culturais. Nessa perspectiva, os sentidos produzidos, a partir das falas apresentadas, são demonstrativos de que, para os alunos participantes do estudo, a aprendizagem da Língua Francesa medeia a comunicação franca, bem como a aprendizagem dos elementos da cultura francesa. 
Após tudo o que foi até aqui exposto sobre os motivos pessoais produzidos pelos alunos investigados, torna-se possível afirmar a partir dos dizeres de Leontiev (1983, p. 230, tradução nossa) que,

A consci ncia como relação a respeito do mundo se apresenta diante de $\mathrm{n} s$ precisamente como um sistema de sentidos e as especificidades de sua estrutura, como especificidades da rela ão entre os sentidos e os significados. $\mathrm{O}$ desenvolvimento dos sentidos um produto do desenvolvimento dos motivos da atividade, o desenvolvimento dos pr prios motivos de atividade determina o desenvolvimento das reais rela es do homem com o mundo, condicionadas pelas circunst ncias objetivo-hist ricas de sua vida. A consci ncia como uma rela ão, não outra coisa que os sentidos que tem para o homem a realidade que se reflete em sua consci ncia. Por consequência, a conscientiza ão dos conhecimentos se caracteriza precisamente pela natureza do sentido que ela tem para o homem.

Assim, através da língua estrangeira o aluno apreende e compreende a realidade na qual se encontra inserido; determina sua identidade cultural, assim como constrói novas visões de mundo que ajudam na formação de uma nova identidade ao se apropriar de uma nova cultura, que vai, provavelmente, se mesclar àquela(s) de origem (ASAGRANDE, 2012).

Faz-se necessário pontuarmos que nos relatos dos alunos além de eles revelarem novas significações (sentidos pessoais) acerca do ensino da Língua Francesa, demostram que os professores que atuam com a disciplina na escola investigada, preocupam-se em criar condições (tarefas e/ou atividades) a fim de os alunos possam associar os conhecimentos prévios que possuem referente aos conceitos trabalhados ao processo de apropriação dos conceitos teórico-científicos da língua em si, mobilizando os alunos pela descoberta e criação de uma postura investigativa do mundo, de "pesquisador", além de uma reflexão linguística e comportamental que, aos poucos, vai lhes dando as condições de agir e interagir de outra maneira, tanto dentro da sala de aula - que é também representação de uma comunidade quanto mais, amplamente, em outros ambientes e contextos (CORREIA, 2019).

Portanto, a partir das significações produzidas pelos alunos e das contribuições teóricas dos autores com os quais dialogamos neste estudo, foi possível observarmos que o ensino de língua estrangeira na escola em que os alunos, participantes deste estudo encontram-se matriculados, cumpre sua função social por ser culturalmente marcado e socialmente ancorado. 
Lendo em francês leio o mundo: significações produzidas por alunos de uma escola pública amapaense sobre ensino da língua francesa para

\section{Considerações finais}

Na busca pela resposta à questão problema deste estudo, a leitura e a análise dos dados produzidos através da entrevista semiestruturada, subsidiadas pelos pressupostos da Teoria Histórico-Cultural/Teoria da Atividade, aproximaram-nos do movimento de produção de sentidos e significados sobre o ensino da Língua Francesa para a comunicação interfronteiriça. Para isso, no decorrer do processo de investigação, delimitamos uma amostra de 5 (cinco) alunos e mediante os discursos destes alunos buscamos analisar essas significações.

As falas dos alunos evidenciaram significações, a priori, manifestadas sobre a necessidade de se aprender a Língua Francesa. Para os alunos, os conhecimentos prévios referentes aos elementos linguísticos da Língua Francesa e da cultura francesa, favorecem à aprendizagem desta disciplina. Tais significações encontram-se relacionadas ao âmbito educacional, social, cultural e humano.

De acordo com os alunos investigados, por meio da aprendizagem da língua estrangeira, eles realizam a leitura de mundo. E esta leitura de mundo contribui para a tomada de consciência da necessidade de uma formação humana, uma formação problematizadora. Para eles, o ensino da Língua Francesa se encontram indissociado do universo cultural e social. É essa indissociabilidade que, no momento das aulas, favorece a realização de aproximações com o mundo da vida, possibilitando aprendizagens com potencial de desenvolvimento.

Nesse contexto, se faz necessário pensar em políticas linguísticas que valorizem o ensino de línguas com enfoque em propostas culturalmente marcadas, que se baseiem, sobretudo, na relação entre língua e cultura. Constatamos que, na verdade, os sentidos produzidos, a partir dos discursos dos alunos investigados, são demonstrativos de que, para os alunos a aprendizagem da Língua Francesa medeia não somente a comunicação franca mas, também, a aprendizagem dos elementos da cultura francesa.

Em síntese, podemos dizer que os sentidos produzidos pelos alunos, residentes na fronteira Brasil/Guiana, os levaram à tomada de consciência de que a aprendizagem da Língua Francesa favorece a comunicação interfronteiriça, promove o diálogo entre povos e contribui para a formação de indivíduos capazes de interagir de forma crítica com pessoas de outras culturas. 


\section{REFERÊNCIAS}

AMBADIANG, J. T. F. Language biographies and the analysis of language situations: on the life of the German community in the Czech Republic. International Journal of the Sociology of Language, n. 162, p. 63-83, 2018.

AGUIAR, W. M. J. (org.). Sentidos e significados do professor na perspectiva sóciohistórica: relatos de pesquisa. São Paulo: Casa do Pedagogo, 2006a.

AGUIAR, W. M. J.; OZELLA, S. Núcleos de significação como instrumento para a apreensão da constituição dos sentidos. Psicologia: Ciência e Profissão, Brasília, v. 26, n. 2, p. 222-245, $2006 b$.

ALAS-MARTINS, S. A intercompreensão de línguas românicas: proposta propulsora de uma educação plurilíngue. Revista Moara. Belém, n. 42, p. 117-126, jul./dez. 2014.

ALMEIDA FILHO, J. C. P. de. Linguística aplicada: Ensino de Línguas e Comunicação. 2. ed. Campinas, SP: Pontes Editores e ArteLingua, 2007.

ARAÚJO JR., B. As formas passivas. In: FANJUL, A.; GONZÁLEZ, N. M. (org.). Espanhol e português brasileiro: estudos comparados. São Paulo, Parábola, 2014. p. 133-157.

ASAGRANDE, S. Restrições de ocorrência do objeto direto anafórico no português brasileiro: gramática adulta e aquisição da linguagem. ReVEL, n. 6, p. 131-163, 2012.

BRASIL. Guia de livros didáticos: PNLD 2015: língua estrangeira moderna: ensino médio. Brasília: Ministério da Educação, Secretaria de Educação Básica, 2014.

BRUN, M. (Re)constru ão identit ria no contexto da aprendizagem de 1 nguas estrangeiras. In: MOTA, K.; SCHEYERL, D. (org.). Recortes interculturais na sala de aula de I nguas estrangeiras. Salvador: EDUFBA, 2004.

CEDRO, W. L.; MOURA, M. O. de. O conhecimento matemático do professor em formação iniciais: uma análise histórico-cultural do processo de mudança. In: MORETTI, V. D.;

CEDRO, W. L. (org.). Educação Matemática e a teoria histórico-cultural: um olhar sobre as pesquisas. Campinas, SP: Mercado de Letras, 2017. p. 87-121.

CORREIA, A. F. C. Escrita Criativa: práticas para o desenvolvimento e competências da escrita no $2^{\circ} \mathrm{CEB}$. Orientador: Pedro Balaus Custódio. 2019. Dissertação (Mestrado em Ensino do $1^{\circ} \mathrm{CEB}$ e em Português e História e Geografia de Portugal do $2^{\circ} \mathrm{CEB}$ ) - Escola Superior de Educação de Coimbra, 2019.

FREIRE, P. Pedagogia da autonomia: saberes necessários à prática educativa. São Paulo: Paz e Terra, 1996.

GARCÍA PAREJO, I.; AMBADIANG, T. La enseñanza de lenguas no maternas en la era de las migraciones: la importancia de las biografías lingüísticas. Doblele. Español lengua extranjera. Revista de Lengua y Literatura, Barcelona, n. 4, p. 22-40, dez. 2018. 
Lendo em francês leio o mundo: significações produzidas por alunos de uma escola pública amapaense sobre ensino da língua francesa para a comunicação interfronteiriça

GASKINS, S., M, P. J; CORSARO, W. A. Theoretical and methodological perspectives.

New directions for child development. San Francisco, CA: Jossey-Bass, 1992. v. 58.

LEONTIEV, A. O desenvolvimento do psiquismo. Lisboa: Livros Horizonte, 1978.

LEONTIEV, A. Activiadade e consciência. In: MAGALHÃES-VILHENA, V. Práxis: a categoria materialista de prática social. Lisboa: Livros Horizonte, 1980. p. 49-77.

LEONTIEV, A. Actividade, consciência, personalidade. Playa, Ciudad de La Habana: Editorial Pueblo y Educación, 1983.

LEONTIEV, A. Uma contribuição à teoria do desenvolvimento da psique infantil. In: VIGOTSKI, L.; LURIA, A.; LEONTIEV, A. N. Linguagem, desenvolvimento e aprendizagem. São Paulo: Ícone, 2018. p. 59-83.

LIMA, J. R de. O desafio da escola em trabalhar com a diversidade. Revista Memento, Três Corações, v. 3, n. 1, jan./jul. 2012.

LONGAREZI, A. M.; FRANCO, P. L. J. Atividade pedagógica na unidade significado socialsentido pessoal. In: LONGAREZI, A, M.; PUENTES, R. V. Fundamentos psicológicos e didáticos do ensino desenvolvimental. Uberlândia, MG: EDUFU, 2017. p. 265-291.

MALAVER, I. Autobiografia linguística. Atitudes, crenças e reflexões para o ensino de línguas. Rev. EntreLínguas, Araraquara, v. 6, n. 1, p. 176-193, jan./jun., 2020.

SARMENTO, S. ReVEL na escola: programa nacional do livro didático de língua estrangeira. ReVEL, v. 14, n. 26, p. 34-48, 2016.

SANTOS, P.G. S; PORTO, J. L. R. Novos usos da fronteira Amapá-Guiana Francesa:

Expectativas de construção e ensaios de cooperação. Revista Geonorte, Manaus, v. 4, n. 12, p. 1152-1168, 2013.

TONET, I. Educação e formação humana. Ideação - Revista do Centro de Educação e Letras da Unioste, Foz do Iguaçu, v. 8, n. 9, p. 9-21, 2006.

VIGOTSKI, L. S. A formação social da mente. São Paulo: Martins Fontes, 2007.

VIGOTSKI, L. S. A construção do pensamento e da linguagem. São Paulo: WMF Martins Fontes, 2009.

WOLF-FARRÉ, P. El concepto de la Biografía Lingüística y su aplicación como herramienta lingüística. Lengua y Habla, n. 22, p. 45-54, 2018. 


\section{Como referenciar este artigo}

CORREIA, M. S.; ARAÚJO, N. A. de; GUIMARÃES JÚNIOR, P. R. Lendo em francês leio o mundo: significações produzidas por alunos de uma escola pública amapaense sobre o ensino da Língua Francesa para a comunicação interfronteiriça. Rev. EntreLínguas, Araraquara, v. 6, n. 2, p. 419-435, jul./dez., 2020. e-ISSN: 2447-3529. DOI: https://doi.org/10.29051/el.v6i2.14205

Submetido em: 20/05/2020

Revisões requeridas: $26 / 07 / 2020$

Aprovado em: 18/08/2020

Publicado em: 30/09/2020 